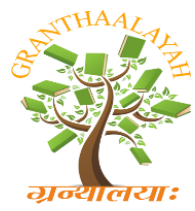

Social

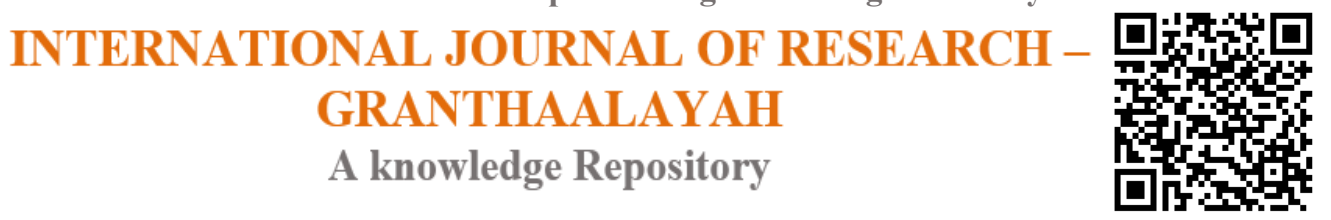

\title{
SCOPE OF ENGLISH LANGUAGE IN INDIA
}

\author{
Ankit Tyagi *1 \\ ${ }^{* 1}$ NET + JRF, PhD Scholar- English, S.R.M. University, Haryana, INDIA
}

\section{ABSTRACT}

English has occupied an important place in our educational system and life of our country. It is the language that continues to dominate the nation. It is generally seen that every language has minimum three components such as sound, structures and vocabulary. But out of three the most vital parts structure which really offers certain meaning with the correct grammatical knowledge as well as structure patterns.

India is a third largest English speaking country. In India English is being perceived as a "mustknow" language. English has now become a ladder for upper social mobility and "a window to the world".

Keywords:

Presentation, Grammar, vocabulary and language description.

Cite This Article: Ankit Tyagi, "SCOPE OF ENGLISH LANGUAGE IN INDIA” International Journal of Research - Granthaalayah, Vol. 3, No. 11(2015): 1-6.

\section{INTRODUCTION}

English is the language of modernization and industrialization but now it is the language of globalization. Observing the rapid change in English language SCRASE remarked it as:-

"English is recognized as a vital global or international language, essential for professional employment and significantly, a key component of the cultural capital of middle class Indians". Increased English language proficiency was considered instrumental in fetching well paid job opportunities. The language thus got recognized as a important link language for national and international purposes."

Regarding the present context teaching and learning process Education Commission has emphatically asserted:

"For the successful completion of the first degree course, a student should possess an adequate command of English, be able to express himself with reasonable ease and felicity, understand lectures in it, and avail himself of its literature. Therefore adequate emphasis will have to be paid on its study as a language right from the school stage". 
Teaching bears the pivotal position in shaping the understanding of the learners. Basically, the problem of learning foreign language is to master over the structures of the language.

Comprehensively speaking, there are basically three steps that have been adopted in teaching structures of English:-

a) Presentation: Presentation of structure basically aims at making the learners understand the lexical as well as the grammatical meaning of a structure.

b) Practice.

c) Application.

Let's analyze these steps to show that what extent they are really adding to the growth of learning. In a teaching process, the learners somehow know the prior knowledge of the structure on which the new structure is built upon. For, before teaching the structure subject-verb-object-extension, the teacher should see that the learners know the structure subject-verb-object. This is what we do call the testing of previous knowledge. The presentation of structure is basically aims at making the learners understand the lexical as well as the grammatical meaning of a structure. This is made with the help of meaningful situations which may be real or artificial. By virtue of these meaningful situations we mean the occasions in real life demanding the use of specified structures, sentence patterns and the vocabulary.

\section{A CHALLENGE IN TEACHING ENGLISH TODAY}

Challenges before the English language teachers in India are enormous and apparent. They should be able to cater to the practical needs of learners to make them competent enough to interact with one another and also to retrieve information all over the world. At present challenges visible before the English language teachers in India are diverse and it is necessary for them to shape up accordingly to meet the demands of the day.

Methods adopted to boost the skills in Present era in English are:-

a) Group Discussions.

b) Debates.

c) Role Plays.

d) Computer assisted language learning (CALL).

However, in our day to day life it is a must for us that we need our skills be sharper as well as finer as we find Dr. Debata (2013): "listening and the reading are passive skills whereas the speaking and the writing are active skills. The Knowledge of the language makes us to know the meaning of isolated words or sentences or the rules of grammar. Talking about the language does not mean knowing language and using it. If we consider language as speech, as the linguists do, then knowing a language means to use its grammatical patterns as well as proper usage." 


\section{IMPORTANCE OF GRAMMAR}

It is really mandatory that we can have the better skills of language only with its grammatical savvy otherwise learning of a language becomes immature as well as floating on the surface of any theoretical knowledge. This ideology is very finely matches with concept of importance with the idea laid by Farjana, (2014) "In language teaching, the most important aspect is grammar teaching. It is true that without the knowledge of grammar anybody can communicate in a foreign language. It will be only for the sake of communication. But the real fact is that without the knowledge of grammar nobody can learn and use a foreign language properly. Without the grammatical knowledge the students will not be able to understand the difference of appropriate use of English and wrong use of English. The knowledge of grammar enables the students to get introduced with sentence pattern. Learning grammar improve the language skills of students. Grammatical knowledge helps the students not only to write proper English but also enables them to produce correct English while speaking." It tends that one can master over expressing English with the help of its grammar enabling students to express themselves correctly on the matters of everyday life.

\section{INNOVATIONS IN ENGLISH LANGUAGE TEACHING}

One of the key issues confronting policy makers, academics, teacher educators And teachers is how to plan, implement, evaluate and sustain effectively innovation from the policy to the classroom levels. Nicholls (1983) defines innovation as 'an Object or practice perceived as new by an individual or individuals, which seeks to Introduce improvements in relation to the desired goals, and that is planned and Deliberate'. Despite the passage of time this definition remains valid today. Edge And Mann (2013: 5) points out that a new idea is in itself not an innovation:

"Innovation demands concentration on process; it demands that we pay as Much attention to how we teach or train as to which topics get covered along the way or the tools that we employ."

They go on to suggest that whether an activity counts as an innovation depends on where and when that action takes place. An activity can count as an innovation if it is new-in-context, so the introduction of peer observations - an established Practice in some contexts - might be considered as an innovation in a situation One of the key issues confronting policy makers, academics, teacher educators And teachers is how to plan, implement, evaluate and sustain effectively innovation From the policy to the classroom levels. Nicholls (1983) defines innovation as 'an Object or practice perceived as new by an individual or individuals, which seeks to Introduce improvements in relation to the desired goals, and that is planned and Deliberate'. Despite the passage of time this definition remains valid today. Edge And Mann (2013: 5) points out that a new idea is in itself not an innovation: Innovation demands concentration on process; it demands that we pay as Much attention to how we teach or train as to which topics get covered along the way, or the tools that we employ.

The principal themes explored at the conference were:

1) Innovations in Continuing Professional Development for English language Teacher educators and teachers: 
- Technology and CPD

- Social media and networking for CPD

- Online and face-to-face mentoring

2) Learning from experience:

- Reflection as a tool for growth

- Classroom-based research

- Alternative practices in assessment and evaluation

- Feedback as a teaching-learning tool

3) Technological resources for language education:

- M-learning in teacher education

- Online teacher education

- Interface of technological and traditional resources

- Digital course design and delivery

- Technology for inclusive and special education

- Technology enabled in-service teacher training (INSET teacher motivation through technology).

Elaine Boyd's reflective paper is designed to help teachers identify and write Good tests. The paper describes the importance of validity, reliability and impact and considers their relationship to ethical practice and how this impacts on the Teacher's responsibility to their students.

Kuheli Mukherjee reviews a recently revised curriculum for the Diploma in Elementary Teacher Education in West Bengal designed to improve the quality of English teaching. The researcher investigates the current reality of Second Language Teacher Education (SLTE) at the elementary level to explore the Conditions necessary for successful implementation of the innovations. The paper discusses three areas: content, approach and the evaluation of elementary SLTE, Where innovations have been proposed.

Pranjana Kalita Nath's paper focuses on promoting reflective skills among Trainee teachers for their professional growth in distance ELT teacher education Programmes. It is an attempt to analyse how activities in print materials in such Programmes can be designed effectively to stimulate reflection, as these are still the dominant medium of instruction in distance ELT programmes in India. The Paper offers some suggestions on how teacher support can be built into distance learning print materials to encourage trainees to reflect.

\section{PRINCIPLES BASED APPROACH FOR ELT}

The notion of a principles-based approach (PBA) for English language teaching (ELT) policies and practices. PBA builds on the current work on language policy and practice, but instead of providing a set of standards, it identifies a set of principles that can help policymakers in diverse contexts develop locally appropriate language policies and practices. Previous work on the standards in relation to language teaching in a variety of contexts has enabled language 
policymakers and administrators to identify aspects of quality language teaching and delivery to measure the success of their programs against. However, the development of standards and the application of these standards across varied contexts can be problematic.

The three knowledge structures that relate to PBA are linguistic theories, theories of language learning and teaching, and frameworks of language policy and planning. Each of these knowledge structures is a set of abstract ideas that are translated into tangible materials and experiences through an interim stage in which the ideas are documented through a set of descriptions and protocols.

Linguistic theories are abstract ideas about what language is and how it works; this knowledge is understood in terms of the study of language (through a creation of Meta language - grammaticsand language descriptions). These linguistic descriptions are then taken into account in developing texts and other material that students are exposed to in their learning environment. In short, different linguistic theories explain language in different ways, which result in different types of language descriptions and influence the choices of texts and grammatical components used in the pedagogical material that students learn and are taught through. Similarly, various theories of learning and teaching explain how (language) learning takes place and how this understanding can be used for teaching purposes. These theories are taught to the teachers during their training programs, and the teachers use them in developing their pedagogical practices. Frameworks of language in education policy also influence the curriculum, which in turn, shapes the syllabi, textbooks, and other teaching and learning resources that the students use in their classes. Thus, the three broad theoretical areas are operational zed in different ways to shape the learningteaching behavior and material that student's experience. These different theories and areas are not necessarily independent of each other and may overlap and/or influence the other areas. Traditional approaches to LPP tend to focus on the policy and planning factors just described; however, PBA builds its framework by integrating not only work on LPP, but also in the areas of linguistic theory and theories of learning and teaching.

\section{CONCLUSION}

To meet the present day challenges in teaching English, first of all, English should not be treated as a subject as it is to be used actively in interacting with one another throughout the world. Earlier methods were adopted just to develop skills such as listening, speaking, learning, writing, and reading but in today's world students are adopting GRE \& TOEFL; where good listening \& speaking skills become an absolute necessity.

Communicative approach was totally neglected by teachers and learners which has become a global demand where students are supposed to communicate across the globe. Teachers should act as facilitators, and should observe how well students organize their thoughts while speaking with their fellow members.

As language changes geographically due to dialectical variations, the teacher should take adequate steps to teach their student about neutral accent and their importance while communication. Clear pronunciation, not perfect pronunciation, is the goal. 
Students are also now facilitated by software to practice pronunciation through phonetics. To achieve the goals of language learning today every college should be provided with language lab, sophisticated equipment like computers, LCD Projectors.

In addition to these, our faculty too should update their knowledge, skills and should acquire thoroughness over their syllabus to meet the demands of globalization since English is seen as a key educational investment in this world. If provided with the latest language teaching tools and with the support of technology, one can teach the language effectively and motivate the students towards language learning.

\section{REFERENCES}

[1] Gardner, Howard (2008) Five Minds for the Future. Boston, Massachusetts: Harvard Business School Publishing.

[2] National Curriculum Framework 2005 Position Paper: National Focus Group on the Teaching of English (2006) New Delhi: NCERT.

[3] National Curriculum Framework for Teacher Education (2009) New Delhi: NCTEbsolute necessity.

[4] Edge, J. and Mann, S. (Eds.) (2013) Innovations in Pre-Service Education and Training for English Language Teachers. London: British Council.

[5] Fullan, M. (2007) The new meaning of educational change (Fourth edition). Abingdon: Routledge.

[6] Hayes, D. (Ed.) (2014) Innovations in the continuing professional development of English language teachers. London: British Council.

[7] Heath, C. and Heath, D. (2011) Switch. London: Random House.

[8] Debata, P. K., (2013). The Importance of Grammar in English Language Teaching -A Reassessment, Language in India.

[9] Farjana, Nowrin. "An experience of teaching English grammar." Retrieved From: http://scholar.google.co.in/scholar?q=nowrin+farjana Kohli, A.L. (1984).Techniques of teaching English. Delhi:

[10] Dhanpat Rai \& Sons Nicholls, A. (1983) Managing educational innovations. London: Allen \& Unwin.plays a vital in today's world. 